\title{
Desigualdades sociales a contraluz: un análisis a partir de trayectorias de clase en Argentina ${ }^{1}$
}

\author{
Desigualdades sociais em contraluz: uma análise \\ baseada nas trajetórias de classe na Argentina
}

\section{Social inequalities in backlit: an analysis based on class trajectories in Argentina}

\author{
iD \\ Leticia Muñiz Terra \\ Universidad Nacional de La Plata, La Plata, Argentina \\ Imunizterra@conicet.gov.ar \\ iD \\ María Eugenia Ambort \\ Universidad Nacional de La Plata, La Plata Argentina \\ maruambort@gmail.com \\ iD \\ Matías lucci \\ Universidad Nacional de La Plata, La Plata, Argentina \\ matiasiu3@gmail.com
}

Resumen: En este artículo, presentamos resultados preliminares de un proyecto de investigación en curso en el cual analizamos la desigualdad social en Argentina para el período 1990-2019. Como punto de partida, proponemos el abordaje de las desigualdades sociales como un fenómeno que es relacional, multidimensional, procesual y multiescalar. Buscando comprender cómo se construyen diferentes formas de la desigualdad entre las clases sociales en un territorio específico y a lo largo del tiempo, adoptamos la perspectiva dinámica de las trayectorias sociales: a) laborales; y b) educativas. Entendemos que el análisis del recorrido educativo y la posterior inserción laboral permite visibilizar de

\footnotetext{
1 Este escrito se enmarca en el proyecto "Trayectorias laborales, generaciones y clases sociales: un análisis de las desigualdades sociales en el Gran la Plata (2003-2019)", 11/H859 y PICT 2011-0928, dirigido por Leticia Muñiz Terra y financiado por Agencia I + D + I y Ministerio de Educación de la Nación. Parte del artículo ha sido elaborado en el contexto de INCASI, Marie Słodowska-Curie, GA No. 691004, coordinado por Pedro López-Roldán. El artículo refleja los puntos de vista de los/as autores/as. Las agencias no son responsables por el uso de la información que contiene.
} 
qué manera se articulan/tensionan los condicionamientos estructurales (modelos económicos y su relación con las posibilidades existentes en el mercado laboral) con las políticas institucionales (relaciones y políticas públicas y privadas de inserción ocupacional) y las acciones de los individuos (estrategias subjetivas para insertarse y permanecer en el mundo del trabajo). En este artículo, enfocamos la mirada en esta última dimensión, en tanto presentamos un análisis centrándonos en las representaciones y acciones de los individuos acerca de sus trayectorias. Entre las principales conclusiones podemos señalar que, mientras la clase media alta presenta trayectorias educativas y laborales relativamente homogéneas, alcanzando los máximos niveles educativos y cargos jerárquicos, y con buenas condiciones de contratación, estabilidad y seguridad social, la clase media trabajadora y la clase trabajadora obrera presentan trayectorias educativas y laborales heterogéneas. Las primeras alcanzan la culminación de la escuela secundaria y la incursión en estudios universitarios y terciarios, y el despliegue de caminos laborales asociados a puestos administrativos formales públicos o privados o a trabajo por cuenta propia, con formas precarias de contratación. Finalmente, la clase trabajadora informal desarrolla trayectorias educativas con pocas credenciales y trayectorias laborales informales muy extensas, que se inician en la infancia.

Palabras clave: Desigualdad social. Clases sociales. Trayectoria laboral. Trayectoria educativa.

Resumo: Neste artigo, apresentamos resultados preliminares de um projeto de pesquisa em andamento no qual analisamos a desigualdade social na Argentina para o período 2003-2019. Como ponto de partida, propomos a abordagem das desigualdades sociais como fenômeno relacional, multidimensional, processual e multiescalar. Para compreender como se constroem as diversas formas de desigualdade entre classes sociais em um território específico e ao longo do tempo, adotamos a perspectiva dinâmica das trajetórias sociais: a) laborais; e b) educativas. Entendemos que a análise da trajetória educacional e da consequente inserção laboral torna visível o modo como os condicionamentos estruturais (modelos econômicos e sua relação com as possibilidades existentes no mercado 
de trabalho) se articulam/tencionam diante das políticas institucionais (relações e políticas públicas e privadas de inserção ocupacional) e as ações dos indivíduos (estratégias subjetivas para a inserção e permanência no mundo do trabalho). Neste artigo, voltamos nosso olhar para esta última dimensão, apresentando uma análise que enfoca as representações e ações dos indivíduos sobre suas trajetórias. Dentre as principais conclusões podemos destacar que, enquanto a classe média alta apresenta trajetórias educacionais e laborais relativamente homogêneas, atingindo os mais altos níveis educacionais e cargos hierárquicos, além de boas condições de contratação, estabilidade e previdência social, a classe média ativa no mercado de trabalho e a classe operária apresentam trajetórias educacionais e laborais heterogêneas. As primeiras concluem o Ensino Médio e adentram o Ensino Superior nos níveis de graduação e pós-graduação, e a implantação de trajetórias laborais associadas a cargos administrativos formais públicos ou privados ou a trabalho autônomo, com formas precárias de contratação. Por fim, a classe trabalhadora informal desenvolve trajetórias educacionais com poucas credenciais e trajetórias laborais informais muito longas, com início na infância.

Palavras-chave: Desigualdade social. Classes sociais. Trajetória laboral. Trajetória educativa.

Abstract: This article presents preliminary results of an ongoing research project in which we analyze social inequality in Argentina for the period 2003-2019. As a starting point, we propose to address social inequalities as a relational, multidimensional, procedural, and multiscale phenomenon. To grasp how the various forms of inequality between social classes are built in a specific territory and over time, we take the dynamic perspective of social trajectories: a) career; and b) education. We see that educational trajectory analysis and the consequent labor insertion makes visible the way in which structural circumstances (economic models and their relation to the existing possibilities in the labor market) are articulated/tensioned in the face of institutional policies (relations and public and private policies for labor insertion) and individual action (subjective strategies for insertion and permanence in the labor market). In this article, we focus our attention on the latter dimension, with an analysis that focuses on representations 
and actions of individuals regarding their trajectories. Among the main conclusions we may highlight that, while the upper middle class has relatively homogeneous educational and career trajectories, reaching the highest educational levels and hierarchical positions, in addition to good hiring conditions, stability, and social security, the middle class active in the labor market and the working class have heterogeneous educational and career trajectories. The former conclude High School and enter Higher Education at undergraduate and graduate levels, and the creation of career trajectories associated with formal public or private administrative positions or with self-employment, which entail poor hiring conditions. Finally, the informal working class follows educational trajectories with poor credentials and it has very long informal career lengths, beginning in childhood.

Keywords: Social inequality. Social classes. Career trajectory. Educational trajectory.

Data de recebimento: 11/05/2020

Data de aprovação: 05/11/2020

4

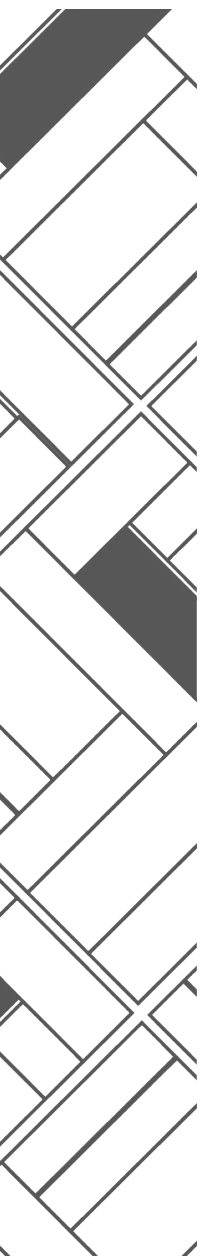




\section{Introducción}

La desigualdad es una de las problemáticas estructurales de las sociedades latinoamericanas que continúa teniendo atención en las ciencias sociales. En este artículo, nos planteamos realizar un aporte para comprender las formas en que se generan, presentan y consolidan a lo largo del tiempo desigualdades de clase en Argentina. Para hacerlo, desarrollamos un estudio de caso instrumental en el Gran La Plata, provincia de Buenos Aires, en el marco del cual realizamos un análisis comparativo de trayectorias laborales y educativas de distintas fracciones de clase en dicho territorio.

Como punto de partida, proponemos el abordaje de las desigualdades sociales como un fenómeno: a) relacional (pues se configura en la relación entre distintos grupos, que en este caso serán la clase media y la clase trabajadora); b) multidimensional (ya que entendemos que la desigualdad debe explicarse considerando múltiples dimensiones de la realidad social -aquí nos centramos en las dimensiones laboral y educativa); c) procesual (ya que se desarrolla a lo largo del tiempo y en contextos culturales e históricos específicos); y d) multiescalar (puesto que expresa la articulación/ tensión entre los condicionamientos estructurales -escala macrosocial-, las relaciones y políticas institucionales -meso-social- y las acciones de los individuos -micro-social).

Buscando comprender cómo se construyen diferentes formas de la desigualdad entre estas clases sociales, en un territorio específico y a lo largo del tiempo, adoptamos la perspectiva dinámica de las trayectorias sociales. Entendemos que el análisis del recorrido educativo y la posterior inserción laboral permite visibilizar de qué manera se articulan/tensionan los condicionamientos estructurales (modelos económicosy su relación con las posibilidades en el mercado laboral) con las políticas institucionales (relaciones y políticas públicas y privadas de inserción ocupacional) y las acciones de los individuos (estrategias subjetivas para insertarse y permanecer en el mundo del trabajo). 
Desigualdades sociales a contraluz: un análisis a partir de trayectorias de clase en Argentina Leticia Muñiz Terra • María Eugenia Ambort • Matías lucci

Esteartículo presenta los primeros resultados deuna investigación exploratoria aún en curso, basada en entrevistas biográficas a distintas clases sociales, para la que delimitamos una muestra intencional de fracciones de clase, siguiendo el esquema de clases de Torrado (1994). En cuanto a la interpretación de las distintas trayectorias sociales de clase, identificamos analíticamente 2 subgrupos en el marco de las clases medias y 2 para las clases trabajadoras.

Organizamos el trabajo del siguiente modo: en la primera parte sintetizamos las modalidades bajo las que las ciencias sociales enfocaron el estudio de las desigualdades de clases; en la segunda, describimos las características del estudio, especificando el modo en el que se construyó la muestra y se desarrolló el trabajo de campo; en la tercera parte se detallan sintéticamente la imbricación de las trayectorias educativas y laborales de cada subgrupo de clases; el artículo finaliza con una serie de reflexiones en las que comparamos las trayectorias de clase e identificamos cómo en ellas se manifiestan las desigualdades sociales en función de las oportunidades de acumulación de ventajas y desventajas ocurridas a lo largo de los diferentes cursos de vida.

\section{La desigualdad social mirada desde la perspectiva de las trayectorias sociales de clase}

Las luchas sociales por conquistar mayores niveles de igualdad y de justicia social en las sociedades capitalistas tienen su correlato, en los estudios sociológicos, en las preguntas respecto de cómo se produce y reproduce la desigualdad social. Existen, en consecuencia, diferentes perspectivas teóricas que, focalizando en múltiples aspectos de la realidad social, analizan e intentan explicar la desigualdad.

Algunas perspectivas enfatizan las experiencias individuales, poniendo el acento en la desigual distribución de capacidades y recursos entre los individuos y apelando, en algunos casos, a la meritocracia y la igualdad de oportunidades como forma de 
Desigualdades sociales a contraluz: un análisis a partir de trayectorias de clase en Argentina Leticia Muñiz Terra • María Eugenia Ambort • Matías lucci

combatir la desigualdad en un contexto de competencia. Estas teorías se enfocan en la distribución de distintos atributos entre los actores sociales y analizan cómo ésta repercute en los desiguales resultados alcanzados por estos en determinados contextos sociales (SEN, 1999).

Los enfoques interaccionistas, por su parte, reconocen que la desigualdad se reproduce en el marco de las relaciones sociales, donde las capacidades y potencialidades individuales se traducen en relaciones de poder. Su preocupación gira en torno a comprender los vínculos sociales que crean desigualdades, refiriéndose tanto a las interacciones entre actores sociales que suponen fuertes condicionamientos a la acción (GOFFMAN, 1981) como a binomios de categorías que circunscriben determinada diferenciación social (como varón/mujer; ciudadano/extranjero; aristócrata/plebeyo) y que pueden persistir a lo largo de una carrera, una vida o una historia institucional (TILLY, 2000). Así, privilegian el análisis sobre las pautas de relaciones entre los actores y los intercambios interinstitucionales desiguales, ya que son estos los que construyen cadenas de dependencia, dispositivos de explotación, acaparamiento de recursos, procesos de exclusión y otras formas de relaciones de poder que permiten el flujo de riquezas de unos grupos hacia otros.

Por último, los trabajos que se concentran en los condicionamientos de la estructura social han resaltado la existencia de estructuras de distribución desigual de los beneficios y las cargas sociales entre los distintos sectores y actores sociales. Su punto de partida supone que la estructura socio-económica suscita el posicionamiento de los individuos en determinados lugares de la sociedad, y que el contexto macro-social explica fundamentalmente la existencia de la desigualdad social (BÁRCENA y PRADO, 2010). Esta mirada acentúa entonces el peso de aquellos condicionamientos (económicos, políticos, sociales, culturales) que no se pueden modificar con la mera agencia individual y en el corto plazo, y que van configurando desigualdades persistentes y posiciones asimétricas que se les imponen a los actores. 
Desigualdades sociales a contraluz: un análisis a partir de trayectorias de clase en Argentina Leticia Muñiz Terra • María Eugenia Ambort • Matías lucci

Los estudios sobre desigualdad social desarrollados en América Latina han puesto históricamente el énfasis en la mirada estructural. Esto responde principalmente a las perspectivas críticas respecto del desarrollo del capitalismo periférico y las consecuencias del paradigma del desarrollo y la modernización en la región, surgidas al calor de la teoría de la dependencia e institucionalizadas en la Comisión Económica para América Latina y el Caribe (CEPAL) en los años 1970 (SOLís y BOADO MARTíNEZ, 2016). Con posterioridad, algunos autores sostuvieron la importancia de poner en diálogo, junto con las posiciones económicas en la estructura social, la influencia de factores como el género, la raza y la etnicidad para comprender las desigualdades en este continente (JELIN, 2014). Así, desde mediados del siglo $X X$, las vastas discusiones sobre el desarrollo (desde las teorías de la modernización hasta el posdesarrollo) han sido criticadas y complementadas por conceptualizaciones locales que invitan a pensar las particularidades del capitalismo periférico y las múltiples interacciones con los antiguos centros coloniales en términos de relaciones de poder (FERNÁNDES, 1973 apud JELIN, 2014).

Ahora bien, cada una de estas perspectivas ha iluminado sobre ciertos aspectos particulares de la problemática de las desigualdades, sin proponer una mirada holística de la cuestión (REYGADAS, 2004). Pero las desigualdades no son resultado de una única causa, pues tienen que ver con las relaciones de poder en distintos planos. Existen, en consecuencia, varios tipos de desigualdades e intervienen en ellas diversos factores. Pueden referirse a las diferencias en los recursos que tienen los agentes para apropiarse de los bienes (desigualdad de activos), a la inequidad en los procedimientos para la distribución de esos bienes (desigualdad de oportunidades) o a la asimetría en la distribución final de los mismos (desigualdad de resultados).

Teniendo en cuenta esto, en este artículo consideramos importante abordar el estudio de la desigualdad de manera integral, es decir, como un fenómeno relacional, multidimensional y multiescalar, que es el resultado de procesos diversos, que se desarrollan a lo 
Desigualdades sociales a contraluz: un análisis a partir de trayectorias de clase en Argentina Leticia Muñiz Terra • María Eugenia Ambort • Matías lucci

largo del tiempo y en contextos culturales e históricos particulares (REYGADAS, 2004; SARAVÍ, 2015).

Decimos que la desigualdad es relacional, ya que necesariamente un colectivo es desigual respecto de otro, y la desigualdad se expresa precisamente en la comparación entre ambos. Además, esta comparación es posible en la medida en que existe una relación entre los dos grupos, que implica tanto reconocimiento como dominación o subordinación. En las sociedades capitalistas y de mercado, en las que el trabajo estructura las condiciones de reproducción de la vida y la sociedad en su conjunto, una de las herramientas de análisis más potentes para comprender esa desigualdad es a partir de los agrupamientos de los individuos en distintas posiciones de la estructura social: a) las clases sociales; $y$ b) las diferentes formas de estratificación social.

La composición, importancia y lucha de clases han sido profundamente estudiadas desde los orígenes de la sociología. Se han desarrollado asíla perspectiva funcionalista durkheimiana, que plantea que la estratificación está basada en: a) la división social del trabajo; b) la mirada estructuralista (marxistas) que está centrada en la idea de que la propiedad o no de los medios de producción da lugar a la conformación de clases (en sí) que se constituyen en el campo de la producción de la vida material, de acuerdo con la inserción diferencial en las relaciones sociales de producción; y c) la teoría vinculada a la acción social (weberiana) que señala que la conformación de las clases en el marco de las sociedades de mercado proviene de las oportunidades económicas que los actores sociales poseen para dar valor en el mercado a sus bienes y su fuerza de trabajo. Las asimetrías en dichas posibilidades son las que dan lugar a relaciones de poder y de prestigio social².

Desde una mirada más contemporánea, autores como Dubet (2011) han indicado que, además de considerar las diferencias y brechas entre la posesión o no de medios de producción, ingresos, patrimonios y prestigio, es necesario considerar cómo

2 No es intención de este artículo abordar las discusiones sobre las clases sociales que se han dado en el marco de las teorías clásicas y contemporáneas de la sociología. Para un desarrollo más detallado de estas cuestiones ver Giddens (1979), Pla (2016) y Dalle (2016). 
Desigualdades sociales a contraluz: un análisis a partir de trayectorias de clase en Argentina Leticia Muñiz Terra • María Eugenia Ambort • Matías lucci

los individuos perciben esa desigualdad y cómo ésta se recrea a partir del cúmulo de pequeñas desigualdades que se reproducen, también, en el plano de la subjetividad. Por su parte, Bourdieu (2012) ha señalado la diferenciación entre clase objetiva y clase subjetiva, planteando que éstas se expresan como dos momentos: a) uno basado en condiciones de existencia homogéneas entre los actores, que tiende a reproducir prácticas semejantes que van conformando los habitus de clase; y b) uno subjetivo que tiene que ver con la representación simbólica y la identificación de los actores entre sí en el espacio social. Para Bourdieu (2012), entonces, la clase es un conjunto de individuos que comparten prácticas y una composición de capital y de habitus similares en el espacio social.

Los estudios sociológicos sobre la estratificación de la sociedad en clases sociales del siglo XX han desarrollado, por su parte, distintas clasificaciones de las clases considerando las categorías ocupacionales de la población. Goldthorpe (1987) ha teorizado sobre la clase poniendo atención en la relación asalariada; Wright (1992), sobre la conformación de las clases y Savage (2014) en torno a la precarización de la vida y el surgimiento del "precariado". Más allá de la perspectiva teórica en la que se inscriba, el análisis de la desigualdad social a través de las clases sociales implica la delimitación de distintas clases que se relacionan entre sí.

Esta diferenciación entre clases se produce y reproduce, además, a varias escalas y a partir de múltiples dimensiones. Es decir, que la desigualdad de clases es relacional y se encuentra conformada por la articulación/tensión entre condicionamientos macroestructurales, relaciones y políticas institucionales, y las acciones de los sujetos sociales (REYGADAS, 2004). Cada una de estas escalas se compone de diferentes dimensiones (trabajo, género, raza, educación, familia, etc.), que se encuentran interconectadas entre sí. La forma en que estas escalas (macro-meso-micro) y sus dimensiones se entrelazan da lugar a configuraciones particulares de la desigualdad social. A su vez, dicha configuración se caracteriza por ir transformándose a lo largo del tiempo, de manera diacrónica. 
Desigualdades sociales a contraluz: un análisis a partir de trayectorias de clase en Argentina Leticia Muñiz Terra • María Eugenia Ambort • Matías lucci

Adscribiendo a esta mirada de la desigualdad como una construcción y reconstrucción relacional, procesual, multiescalar y multidimensional, en este artículo proponemos para su abordaje la perspectiva de las trayectorias sociales. Esta forma de comprender la realidad promueve el estudio de la articulación/tensión de la multidimensionalidad y de las distintas escalas a lo largo del tiempo y del espacio.

\section{Metodología}

Para el análisis de las desigualdades sociales, partimos de la perspectiva biográfica y nos abocamos a la reconstrucción y el análisis de trayectorias de actores sociales pertenecientes a las clases medias y trabajadoras. Este enfoque metodológico resulta pertinente, en tanto permite comprender las desigualdades a partir de entrelazar en el análisis la estructura de oportunidades del mundo externo (elementos objetivos o dimensión macro social) las políticas y relaciones institucionales (escala meso-social) y el conjunto de disposiciones, capacidades y acciones que los sujetos ponen en juego en sus trayectorias (elementos subjetivos o micro-sociales). Una dimensión central en este proceso analítico es la temporalidad, en tanto permite observar cómo se tensionan e imbrican estas dimensiones a lo largo del tiempo (MUÑIZ TERRA, 2012). Así, la particularidad del análisis de clases que presentamos está centrada en la mirada diacrónica de trayectorias que posibilita aprehender la configuración de las clases y sus cambios y permanencias en la temporalidad (BERTAUX, 1981).

En relación a la dimensión subjetiva de las trayectorias, resulta significativo señalar que, desde la aproximación biográfica, todo trayecto vital que se recupera mediante entrevistas biográficas puede ser considerado como un entrecruzamiento en la temporalidad de múltiples líneas biográficas más o menos autónomas y dependientes unas de las otras (GODARD, 1998). La educación, el trabajo y la vida familiar son tanto historias paralelas como imbricadas, hilos que tejen la madeja biográfica. 
Desigualdades sociales a contraluz: un análisis a partir de trayectorias de clase en Argentina Leticia Muñiz Terra • María Eugenia Ambort • Matías lucci

El análisis biográfico suele enfocar la mirada en alguna/s de estas trayectorias, dado que sería imposible recuperar en profundidad las particularidades de todas las líneas existentes. Inmersos en esta posición, centramos aquí la atención en dos líneas biográficas particulares -a) la laboral; y b) la educativa- y analizamos las articulaciones/tensiones que éstas van atravesando en su desarrollo, produciendo, reproduciendo y cristalizando una apropiación desigual de recursos materiales y simbólicos.

Para este estudio se diseñó una muestra intencional conformada por:a) mujeresyvarones; b) adultos/asentre 30 y 65 años; $y c)$ personas que se encontraran económicamente activos/as al momento de la entrevista (ocupado/as o desocupado/as). Esta delimitación propició el desarrollo de un trabajo de campo conformado por 20 entrevistas biográficas con adultos/as de clases medias y trabajadoras.

El recorte de adultez desde los 30 años en adelante fue delimitado siguiendo el concepto de madurez ocupacional, que hace referencia a la edad promedio mínima a partir de la cual puede considerarse que el conjunto de trayectorias ya ha desarrollado la mayor parte del proceso de maduración en la inserción laboral (ERIKSON y GOLDTHORPE, 1993). Los 65 años de edad son el límite establecido por la ley para pertenecer formalmente a la población económicamente activa en Argentina.

La asignación de las personas entrevistadas a las distintas clases sociales estuvo orientada por la tradición sociológica vinculada a los estudios de la estructura y la movilidad social, que históricamente ha operacionalizado a las clases basándose en la ocupación (GOLDTHORPE, 1987; WRIGHT, 1992; ERIKSON y GOLDTHORPE, 1993). Considerando esta delimitación, y con la intención de garantizar heterogeneidad de posiciones y situaciones en la esfera laboral, seleccionamos a las personas buscando que pertenecieran a hogares cuyo principal sostén del hogar (PSH) pudiera ser incluido en alguna de las fracciones de clase media o trabajadora identificadas por Torrado (1994) en el esquema a continuación. Asumimos así que las personas entrevistadas pertenecen a la clase social del PSH (Tabla 1). 
Desigualdades sociales a contraluz: un análisis a partir de trayectorias de clase en Argentina Leticia Muñiz Terra • María Eugenia Ambort • Matías lucci

Tabla 1. Agrupamiento de clases sociales según condición socio-ocupacional del PSH

\begin{tabular}{|c|c|c|}
\hline & Condición Socio Ocupacional (CSO) & Reagrupamiento \\
\hline 1 & Directores/as de Empresas & \multirow{7}{*}{ Clases Medias } \\
\hline 2 & Profesionales en Función Específica & \\
\hline 3 & Propietarios/as de Pequeñas Empresas & \\
\hline 4 & Cuadros Técnicos y Asimilados & \\
\hline 5 & Pequeños/as Productores/as Autónomos/as & \\
\hline 6 & Empleados/as Administrativos/as y Vendedores/as & \\
\hline 7 & Trabajadores/as Especializados/as Autónomos/as & \\
\hline 8 & Obreros/as Calificados/as & \multirow{5}{*}{$\begin{array}{c}\text { Clases } \\
\text { Trabajadoras }\end{array}$} \\
\hline 9 & Obreros/as No Calificados/as & \\
\hline 10 & Trabajadores/as Inestables & \\
\hline 11 & Empleados/as Domésticos/as & \\
\hline 12 & Sin Especificar & \\
\hline
\end{tabular}

Fuente: Adaptada de Torrado (1994).

Este esquema de clases, construido sobre la base de la categoría de ocupación, el sector de actividad, el tamaño del establecimiento y la rama de actividad, resulta significativo, dado que permite caracterizar la especificidad de las relaciones de clase en Argentina, al dar cuenta de la existencia de un sistema de producción definido por la articulación de relaciones de producción capitalistas y relaciones mercantiles simples, propias de economías con heterogeneidad estructural.

Ahora bien, dado que como señalamos el análisis de trayectorias implica recuperar en la temporalidad la articulación/ tensión entre los condicionamientos macroestructurales, las relaciones y políticas institucionales y las acciones de los individuos, creemos pertinente señalar que, por una cuestión de extensión (de páginas), en este artículo nos enfocamos específicamente en las representaciones y acciones subjetivas (dimensión micro-social). A pesar de ello, el análisis de las trayectorias y sus desigualdades fue realizado considerando los contextos macro y meso-sociales.

En las interpretaciones realizadas consideramos así que las trayectorias de clase se desplegaron en una economía periférica caracterizada por la presencia de modelos productivos y un 
Desigualdades sociales a contraluz: un análisis a partir de trayectorias de clase en Argentina Leticia Muñiz Terra • María Eugenia Ambort • Matías lucci

mercado laboral segmentado en 3 polos: el primario, que involucra mayor tecnología, aglutina sectores propios de actividades modernizadas, posee alta productividad, presenta mayor calidad de los empleos y sus trabajadores/as están cubiertos/as por el sistema de protección social con altos salarios; el secundario, que presenta actividades económicas con menor tecnología, los puestos de trabajo tienen un carácter precario o informal y están por fuera de la protección social estatal; y un tercer polo que está compuesto por la "masa marginal" que se caracteriza por trabajos aún más informales que los anteriores (SALVIA, 2013).

Asimismo, consideramos que las políticas laborales y educativas en Argentina han ido variando entre la universalidad y la focalización. Recuperamos así la idea de la transición desde una política que interpelaba a los/as trabajadores/as y beneficiarios/as de planes sociales en tanto trabajadores/as insertos/as en el sistema, hacia una política cuyo sujeto era un otro, al que se lo separaba del conjunto social (GRASSI y HINTZE, 2018). Es decir, consideramos que las trayectorias se construyeron en un trasfondo cambiante con una importante tendencia hacia una individualización (BECK y BECK GERNSHEIM, 2003) e individuación (MARTUCCELLI y DE SINGLY, 2012) institucional.

En cuanto al trabajo de campo propiamente dicho, se realizaron entrevistas biográficas en el aglomerado Gran La Plata, Buenos Aires, Argentina; contexto regional relevante ya que sus indicadores laborales (empleo, desempleo, subocupación, precariedad, informalidad, etc.) presentan similitudes con los indicadores nacionales y con los grandes aglomerados urbanos del país. Esta situación es la que nos permite hacer una extrapolación razonable (PATTON, 2002) 3 y hablar de la desigualdad social y de las trayectorias de clase en Argentina.

A los fines de conocer en profundidad cómo se configura y reproduce la desigualdad social entre las clases desde una mirada subjetiva, relacional y dinámica, en el proceso analítico hemos

3 La idea de extrapolación razonable remite a la posibilidad de que los resultados de una investigación cualitativa con estudios de caso puedan ser utilizados para comprender la realidad social, dado que ese caso es un reflejo mismo de la realidad. 
Desigualdades sociales a contraluz: un análisis a partir de trayectorias de clase en Argentina Leticia Muñiz Terra • María Eugenia Ambort • Matías lucci

procedido a unir los relatos de los grupos de las dos clases sociales en dos subgrupos por clase (Tabla 2).

Tabla 2. Agrupamiento de clases sociales

\begin{tabular}{|c|c|c|}
\hline Grupo & \multicolumn{2}{|c|}{ Fracción de clase del PSH } \\
\hline 1 & $1,2,3$ & Media alta \\
\hline 2 & $4,5,6,7$ & Media trabajadora \\
\hline 3 & 8,9 & Trabajadora obrera \\
\hline 4 & 10,11 & Trabajadora informal \\
\hline
\end{tabular}

Fuente: Elaborada por los autores.

La conformación de los grupos unificando fracciones de clases se fundó en el criterio relacional, pues se basó en la conjunción de personas cuyos relatos biográficos tuvieran similares recorridos, representaciones y valoraciones sobre sus trayectorias de clase y sobre las trayectorias de las otras clases sociales.

En cuanto al análisis del material cualitativo, realizamos un análisis de acontecimientos biográficos y momentos bifurcativos (MUÑIZ TERRA, 2018). Esto posibilitó captar la imbricación de las múltiples dimensiones y escalas que conforman las trayectorias educativas y laborales de los/as entrevistados/as.

\section{Análisis de las trayectorias de las clases medias y trabajadoras en Argentina}

En este apartado recuperamos la manera en que la dimensión educativa se imbrica con la ocupacional a lo largo del tiempo.

Los ejes que contribuyeron a delinear analíticamente la relativa homogeneidad al interior de cada grupo, y que los diferencian entre sí, son: 
Desigualdades sociales a contraluz: un análisis a partir de trayectorias de clase en Argentina Leticia Muñiz Terra • María Eugenia Ambort • Matías lucci

1. Los niveles alcanzados en la trayectoria educativa y las formas que adquiere el itinerario escolar;

2. La forma en que se realizan y valoran los aprendizajes para el trabajo, las credenciales educativas y cómo éstas se transforman (o no) en oportunidades y ventajas para la inserción laboral;

3. Las entradas, salidas y permanencia en el mercado de trabajo, los recorridos ocupacionales y cómo se pone en juego el cuerpo en cada grupo; y

4. El valor atribuido a las distintas redes sociales establecidas y la forma en que se perciben e interpretan las dimensiones macro y meso-social en relación a la estructura de oportunidades disponibles ${ }^{4}$.

\section{Trayectorias del Grupo 1: recorridos de la clase media alta}

\section{6}

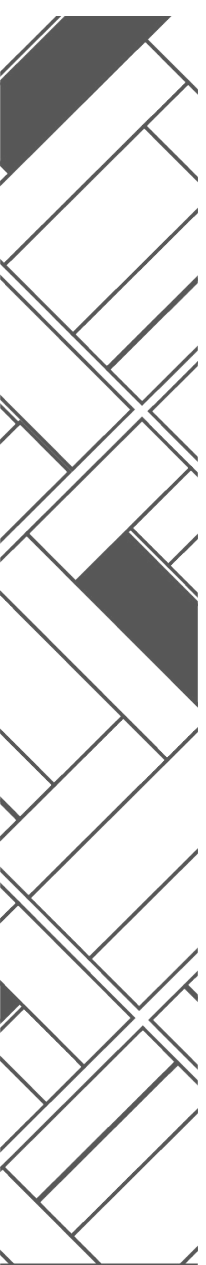

El grupo 1 está conformado por directores/as de empresas, profesionales en función específica y propietarios/as de pequeñas empresas. Es el sector mejor posicionado en el mercado laboral. Estas personas alcanzan trabajos formales o inserciones con seguridad social y certezas ocupacionales y cuentan, en la mayor parte de los casos, con educación superior de grado y posgrado. Las trayectorias laborales y educativas de este grupo dan cuenta de una relevante homogeneidad.

Las familias de origen presentan, en cambio, cierta heterogeneidad pues mientras en algunos hogares madres, padres y abuelos/as no terminaron la educación media (o la finalizaron con cierto retraso), otros grupos familiares presentan educación universitaria incompleta o culminada. En cuanto a las inserciones laborales, también se observan diferencias, pues mientras en algunas familias se realizaron actividades en el marco del mercado

4 Cabe aclarar que, si bien nuestro análisis se centra en las trayectorias sociales como objeto de investigación, en la narración utilizamos de manera indistinta este concepto y un conjunto de nociones tales como recorrido, itinerario, caminos, etc., que en otras investigaciones refieren exclusivamente a la narración del sujeto sobre su vida. Esto nos permite enriquecer la construcción narrativa del texto. 
Desigualdades sociales a contraluz: un análisis a partir de trayectorias de clase en Argentina Leticia Muñiz Terra • María Eugenia Ambort • Matías lucci

de trabajo formal, en otras aparece una combinación de trabajos formales e informales. En relación a la familia conformada por las personas entrevistadas, encontramos una diversidad de situaciones: a) presencia o ausencia de cónyuges; y b) existencia de 2 o 3 hijos/as que asisten a la educación primaria, media o universitaria.

Ahora bien, si nos concentramos en las trayectorias educativas de estas personas, podemos señalar que asistieron a escuelas primarias tanto públicas como privadas. Su elección estuvo habitualmente a cargo de las madres, quienes escogían las instituciones escolares en función de la organización del trabajo doméstico de sus hogares.

En los recuerdos de esta primera etapa educativa se entrelazan el cariño de los/as docentes, con los edificios amplios y con lugar de esparcimiento y una composición áulica heterogénea, en la que había algunos/as compañeros/as con más recursos económicos y académicos y niños/as con pocos útiles, y deberes en ocasiones incompletos, dado que contaban con escaso tiempo disponible, pues solían colaborar trabajando en los negocios familiares (almacenes, verdulerías, kioscos). Las diferencias de clases y las relaciones interclases se hacían así presentes en el mundo escolar.

Los pasajes a la educación media se transformaron en tránsitos alcanzados con esfuerzo, dedicación y algunas privaciones, pues, en comparación con las primarias, las escuelas secundarias fueron escogidas considerando especialmente cuestiones académicas y relacionales, vinculadas a sociabilidades y gustos propios de las clases medias acomodadas: las exigencias académicas se combinaron con hobbies, paseos, estudio de idiomas y consumos compartidos o deseados según las posibilidades familiares. Más allá del esfuerzo, este pasaje era vivido como un acontecimiento que debía suceder sin contratiempos, pues el tránsito hacia la educación media era un pasaje naturalizado en este grupo social.

Una vez concluida la escuela secundaria, transitaron hacia la educación superior, que era imaginada y valorada tanto como una posibilidad para la inserción definitiva en el mercado laboral como una oportunidad de alcanzar una formación que les posibilitara 
Desigualdades sociales a contraluz: un análisis a partir de trayectorias de clase en Argentina Leticia Muñiz Terra • María Eugenia Ambort • Matías lucci

cierto ascenso social. La decisión de continuar estudiando fue estimulada por el grupo familiar, que acompañó la decisión garantizando los soportes necesarios (casa, alimento, vestimenta, traslados, etc.) para concurrir a la universidad.

Estos estudios fueron desarrollados en universidades públicas y su elección estuvo orientada por la vocación y las posibilidades de inserción ocupacional que podían brindar. La clase ubicada en la cúspide de la estructura social se enfrentó así a un mundo nuevo y diverso, en el que debía acostumbrarse al anonimato y a la autonomía para elegir horarios y a comprometerse consigo misma para avanzar y culminar los estudios superiores.

Ante la voluntad o, en ciertos casos, frente a la necesidad de costear sus propios gastos (libros, fotocopias, salidas, etc.), o con la idea de tener experiencias de trabajo, algunos/as de los/as entrevistados/as se insertaron, durante sus estudios universitarios, en el mercado laboral en actividades de medio tiempo que les permitían también estudiar. Estos primeros pasos en la trayectoria laboral se desplegaron entonces bajo soportes individuales o institucionales informales: clases particulares a domicilio, atención de bares y librerías, venta por catálogo, cuidado de niños/as, asistencia administrativa en consultorios, etc., fueron las primeras experiencias laborales de las clases medias altas. Estos empleos fueron abandonados ante la necesidad de disponer de tiempo para estudiar y culminar la universidad, o para pasar a inserciones formales más estables.

Yo me hice una parte estudiando y otra trabajando. Mientras estudiaba, trabajaba en un estudio jurídico de secretaria, también cuidé chicos y di clases en un jardín de infantes... Después, empecé de a poquito, cada vez más tiempo, en un estudio jurídico. Aprendí mucho de lo que es la práctica, de lo que es el abogado litigante, que no es toda la abogacía, trabajando y la teoría la estudiaba de los libros. Muchos otros saberes, que están en los libros, no siento haber obtenido en la facultad... Mucho lo aprendí en la calle, haciendo tribunales. (Entrevista No. 13) 
Desigualdades sociales a contraluz: un análisis a partir de trayectorias de clase en Argentina Leticia Muñiz Terra • María Eugenia Ambort • Matías lucci

En estas experiencias universitarias y primeras inserciones laborales los/as entrevistados/as valoraron especialmente el esfuerzo personal que hicieron para estudiar y trabajar al mismo tiempo, y visibilizaron sus logros como méritos individuales, naturalizando los soportes familiares e institucionales a los que pudieron acceder. Se vincularon además con muchas personas que transitaban condiciones y experiencias de clase disímiles: como quienes abandonaron los estudios por la necesidad de trabajar.

Medio que me habían enseñado que uno estudia y después trabaja, y bueno [ríe], era como que así había que hacer la vida... y sabía que podía. Me gustaba la posibilidad también de tener un diferencial de plata, más allá de que no me faltaba nada. (Entrevista No. 15)

La trayectoria educativa de los/as entrevistados/as de esta clase social continuó luego, en algunos casos, en estudios de posgrado en universidades públicas y/o privadas que no siempre fueron finalizadas, pero que les permitieron acceder a conocimientos específicos vinculados con sus actividades laborales.

Lastrayectoriasocupacionales desarrolladas enformaposterior a las primeras inserciones fueron heterogéneas en cuanto a los sectores de actividad y homogéneas en relación a las condiciones de contratación. Algunas personas realizaron toda su trayectoria en el sector privado, otras lo hicieron en el sector público, o fueron alternando entre ambos. En líneas generales, todos/as alcanzaron un empleo formal (en relación de dependencia) o trabajaron de manera independiente en forma estable y permanente (haciendo sus propios aportes y pagando su obra social o prepaga).

En estas transiciones ocupacionales, los/as entrevistados/ as dispusieron no sólo de los saberes aprendidos en las carreras universitarias de grado y posgrado, sino también de sus saberes extracurriculares y actitudinales: los idiomas, los conocimientos artísticos, el manejo de dispositivos y saberes informáticos, la 
Desigualdades sociales a contraluz: un análisis a partir de trayectorias de clase en Argentina Leticia Muñiz Terra • María Eugenia Ambort • Matías lucci

proactividad y la "gestión de sí" se transformaron en elementos habitualmente puestos en juego en el camino laboral.

Un grupo de entrevistados/as pusieron su formación universitaria al servicio de organismos públicos y desarrollaron sus trayectorias como psicólogos/as, abogados/as, contadores/as, ingenieros/as transitando por distintas dependencias estatales. En este contexto, algunos/as pudieron hacer una carrera laboral, ascendiendo paulatinamente, hasta ocupar puestos de responsabilidad y supervisión con 30 empleados/as a cargo. Estos ascensos fueron alcanzados porque las instituciones públicas tenían una carrera delimitada para este tipo de trabajadores/as con saberes institucionalizados certificados y con importantes desarrollos actitudinales y autogestivos.

Otros/as entrevistados/as, por su parte, desplegaron una trayectoria independiente. Tras trabajar en relación de dependencia en instituciones privadas (empresas constructoras, compañías de logística, etc.) o públicas, decidieron comenzar su emprendimiento organizando empresas propias que empezaron siendo pequeñas $y$, en algunos casos, se transformaron en medianas y/o grandes, con hasta 350 empleados. En estos casos, la independencia fue motivada por la búsqueda de desarrollo y crecimiento personal.

Gráfico 1. Trayectorias de clase media alta (TC1)

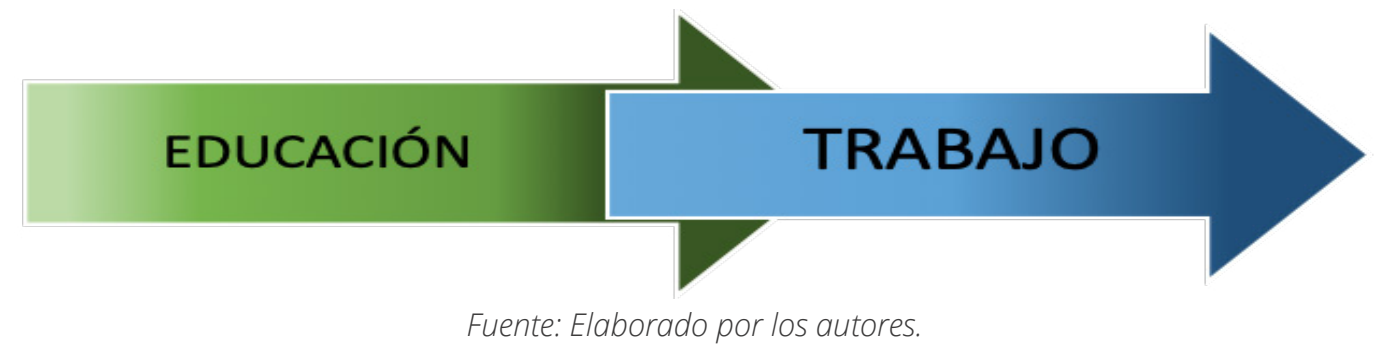

El Gráfico 1 visibiliza las trayectorias del grupo 1, en donde se observa un amplio desarrollo de la trayectoria educativa con saberes que se van intensificando con el tiempo y una trayectoria laboral que comienza en paralelo o luego de finalizada la educación formal y que se va consolidando de manera formal a lo largo del tiempo. 


\section{Trayectorias del grupo 2: itinerarios de la clase media trabajadora}

Este grupo está conformado por trabajadores/as que se desempeñan como técnicos/as, o pequeños/as productores/as autónomos/as, empleados/as administrativos/as, vendedores/as y trabajadores/as especializados/as cuentapropistas. Es el sector del mercado laboral que oscila entre la formalidad y la precariedad laboral, que posee una instrucción media finalizada y una educación superior abandonada o culminada luego de muchos años de estudio. De esta forma, si bien presentan cierta homogeneidad en términos de transiciones educativas, las trayectorias laborales muestran, en contraste, una marcada heterogeneidad.

En general, los integrantes de las familias de origen (madres, padres, abuelos/as) no culminaron la educación media y presentan trayectorias laborales entre inestables y precarias en el sector privado, o formales en el sector público. La composición de sus propias familias se caracteriza por la presencia de cónyuges que se encuentran insertos/as en el mercado de trabajo y que poseen nivel de estudio medio, con quienes tienen 2 o 3 hijos que asisten a la educación primaria, media o universitaria.

En cuanto a las trayectorias educativas de los/as entrevistados/ as, podemos comenzar señalando que se observa un tránsito por escuelas primarias, tanto públicas como privadas. La elección del tipo de institución se basó en distintas consideraciones dentro del seno familiar pues mientras las escuelas públicas eran escogidas por su cercanía con el hogar, las escuelas privadas -habitualmente católicas y parroquiales- eran escogidas con la esperanza de que brindaran una buena calidad educativa. La formación religiosa era, en consecuencia, un elemento secundario en dicha elección.

Las experiencias en la primaria son recordadas con alegría, como un período de la infancia que disfrutaron con compañeros/as de distintas clases sociales. Las diferencias de clase que se hacían visibles en el contexto áulico por la carencia de útiles escolares y, 
Desigualdades sociales a contraluz: un análisis a partir de trayectorias de clase en Argentina Leticia Muñiz Terra • María Eugenia Ambort • Matías lucci

en algunos casos, en comportamientos violentos, no significaban un obstáculo para la diversión, la amistad y el aprendizaje.

La transición hacia la educación media se caracterizó por un recorrido continuo en el que primó la elección de la educación pública, de la cual se esperaba una buena formación en un contexto de gratuidad. En los espacios educativos de nivel secundario, la diversidad de clases que había estado presente en el nivel primario comenzó a dispersarse, pues los/as entrevistados/ as no percibían mucha diferencia entre sus compañeros/as, o cuando las había eran sólo de matiz. En estas escuelas todos/ as tenían más o menos los mismos rendimientos académicos y similares recursos económicos, culturales y sociales. Algunos/as continuaron su formación en la educación superior que, en todos los casos, fue realizada en una institución pública. El ingreso y la permanencia en los estudios superiores fueron vividos como un tránsito difícil, en el que se requería mucha dedicación y estudio, pues el nivel académico requerido no había sido adquirido en la escuela secundaria pública.

Aunque las elecciones disciplinares iniciales fueron promovidas por mandatos o deseos familiares, o se escogieron sin un conocimiento concreto, luego se produjeron cambios para ajustar las expectativas a los proyectos educativos, generando en algunos casos desaliento y retraso. En esta etapa, los itinerarios educativos superiores se transformaron en zigzagueantes, con intermitencias breves o con interrupciones prolongadas y derivaron, en algunos casos, en abandonos posteriores. A pesar de que en otros casos posibilitó la culminación, ésta fue alcanzada luego de varios años de estudio, combinada con trabajo de tiempo completo y formación de una familia propia.

Estas idas y vueltas y el abandono de los estudios superiores limitaron, en ciertos casos, el acceso a saberes específicos. Asimismo, esta situación fue potenciada por las características que asumieron los aprendizajes realizados en la escuela secundaria, habitualmente considerados como conocimientos enciclopédicos, muy generales y teóricos. Todo esto condicionó el ingreso al 
Desigualdades sociales a contraluz: un análisis a partir de trayectorias de clase en Argentina Leticia Muñiz Terra • María Eugenia Ambort • Matías lucci

mercado laboral, que se produjo entre los últimos años del colegio secundario y el primer año de los estudios terciarios o universitarios.

\begin{abstract}
Desde que llegué a La Plata para estudiar, comencé a trabajar por lo económico, porque qué se yo, me mandaban dinero, pero muchas veces no llegábamos a tener una dieta saludable todo el tiempo. Comencé... Tenía un contrato que era muy malo... había cierta parte en blanco, cierta parte no, pero con eso yo podía estudiar... o sea podía comprarme todos los materiales que precisaba para la facultad, tenía que cursar menos porque no podía... como trabajaba de noche para cursar de día, no podía hacer las 6 materias anuales, capaz hacía 3 materias. (Entrevista No. 42)
\end{abstract}

Las trayectorias laborales de esta clase son heterogéneas, pues se observa el recorrido de distintos caminos ocupacionales. Los primeros trabajos fueron conseguidos a través de familiares, amigos y conocidos, se desarrollaron siempre en la economía informal e implicaron la realización de diversas labores: atención al público, colaboración en talleres mecánicos o de artesanías, ventas, etc., eran algunas de las actividades realizadas a cambio de los ingresos necesarios para el sostenimiento de la vida familiar. Dichas inserciones se producían en forma paralela a los estudios -secundarios, terciarios o universitarios- y significaban que los/as entrevistados/as debían atravesar una jornada diaria intensa que se dividía entre el mundo laboral y educativo.

- Tu vida era trabajar de siete de la tarde a dos, tres de la mañana, y después ¿ir a cursar a la facultad?

- Sí... iba dormido. El primer parcial lo entregué en blanco, y el segundo lo volví a entregar en blanco, porque no podía estudiar, llegaba muerto a mi casa... (Entrevista No. 8)

Esta situación colaboró, con el tiempo, con la decisión que tomaron algunos/as de dejar los estudios, dado el estrés y el 
Desigualdades sociales a contraluz: un análisis a partir de trayectorias de clase en Argentina Leticia Muñiz Terra • María Eugenia Ambort • Matías lucci

cansancio producido por esta división y los escasos rendimientos académicos.

Luego deestas primerasincursionesocupacionales, ycon mayor tiempo disponible por el abandono, la interrupción o la culminación retrasada de los estudios superiores, las inserciones laborales se fueron encaminando hacia cierta estabilidad y formalidad en las condiciones laborales, o bien hacia una precariedad permanente. Así, las trayectorias laborales de mediano y largo plazo identificadas en este grupo pueden dividirse en 3 subgrupos: a) quienes hicieron algún rodeo por trabajos informales hasta que lograron ingresar de manera precaria y luego formal a distintas instituciones públicas; b) las trayectorias de quienes pasaron por 2 o 3 trabajos en el sector privado sin lograr transformarse en asalariados/as; y c) los recorridos autónomos que con el tiempo adquirieron rasgos permanentes de precariedad.

En relación con el subgrupo $a$, entre los que se insertaron en el Estado puede establecerse a su vez una distinción entre: i) quienes se insertaron en instituciones públicas luego de culminar los estudios universitarios, sin lograr utilizar sus saberes disciplinares en los puestos de trabajo conseguidos; y ii) aquellos/as que lograron ingresar en la administración pública sin haber finalizado su formación superior. Estos puestos de trabajo presentaron limitaciones en relación al desarrollo profesional, pues sólo habilitaban la posibilidad de cumplir roles de asistencia técnica o de mensajería y cadetes en determinados sectores y oficinas estatales. Estos ingresos al sector público fueron habilitados a través de redes familiares o amicales, y fueron inicialmente con contratos precarios. Con el paso de los años pasaron a la planta de empleados transitoria donde algunos/as se han quedado y otros/as pasaron de transitorios a permanentes y formales. Esta situación no significó necesariamente posibilidades de ascender y cambiar de puesto, pues las carreras públicas de este segmento de la administración pública cuentan con pocos escalafones para la movilidad. 
Desigualdades sociales a contraluz: un análisis a partir de trayectorias de clase en Argentina Leticia Muñiz Terra • María Eugenia Ambort • Matías lucci

En cuanto al subgrupo b, quienes se insertaron en el sector privado tuvieron un derrotero aún más incierto hasta alcanzar una estabilidad relativa, en la que también estaba presente la precariedad. Pasaron por 2 o 3 trabajos informales con duraciones que podían variar entre 2, 3 y 4 años, que eran soportados porque la situación de la economía familiar era apremiante (los padres y/o madres estaban sin trabajo o ya tenían responsabilidades en las familias que habían conformado). Las desvinculaciones de estos trabajos fueron provocadas por varias causas: i) bajos salarios; ii) maltratos; iii) exigencias de trabajar más horas de las convenidas; y/o iv) pocas posibilidades de crecer y desarrollarse fueron los motivos habitualmente mencionados. Este tránsito por actividades informales dio lugar, posteriormente, a empleos en los mismos sectores, pero con mayores certezas, dadas las experiencias acumuladas y las relaciones establecidas con los patrones. Así, las trayectorias en el sector privado -ya sea en la atención de comercios, el manejo de transportes públicos (buses), el servicio de mensajería, etc.- adquirieron con el tiempo cierta estabilidad, pues el trabajo en el marco de un contrato por tiempo determinado (que era renegociado de manera recurrente cada 2 o 3 años) comenzó a ser la norma. Estas inserciones limitaron, por otro lado, la posibilidad de hacer una carrera ascendente, pues la única movilidad posible era la rotación entre puestos de trabajo.

Y con respecto al subgrupo $c$, las trayectorias cuentapropistas muestran, por su parte, ciertas particularidades, ya que se desplegaron principalmente en el marco de la economía informal y en ocasiones esta situación era parte de una elección personal. En algunos casos, en estos recorridos se privilegió el trabajo especializado (joyería, cerámica, trabajos sobre cueros, etc.) que elegían a pesar de la informalidad laboral. En otros, la especialidad de su trabajo (cuidado de enfermos/as o de adultos/as mayores) era, en cambio, vivenciada como una condición limitante de su inserción en el mercado de trabajo.

Ahora bien, la heterogeneidad identificada en estas trayectorias tiende a desdibujarse cuando observamos la valoración que unos/ 
Desigualdades sociales a contraluz: un análisis a partir de trayectorias de clase en Argentina Leticia Muñiz Terra • María Eugenia Ambort • Matías lucci

as y otros/as les otorgan a los recorridos realizados, pues todos/ as los/as entrevistados/as han subrayado los esfuerzos personales y las capacidades puestas en juego para desplegar su camino laboral, poniendo en un segundo plano los soportes institucionales con que contaron. Las posibilidades e imposibilidades transitadas han sido así interpretadas como consecuencias de sus acciones personales y no de los contextos meso y macro-sociales que les acompañaron.

Gráfico 2. Trayectorias de clase media trabajadora (TC2)

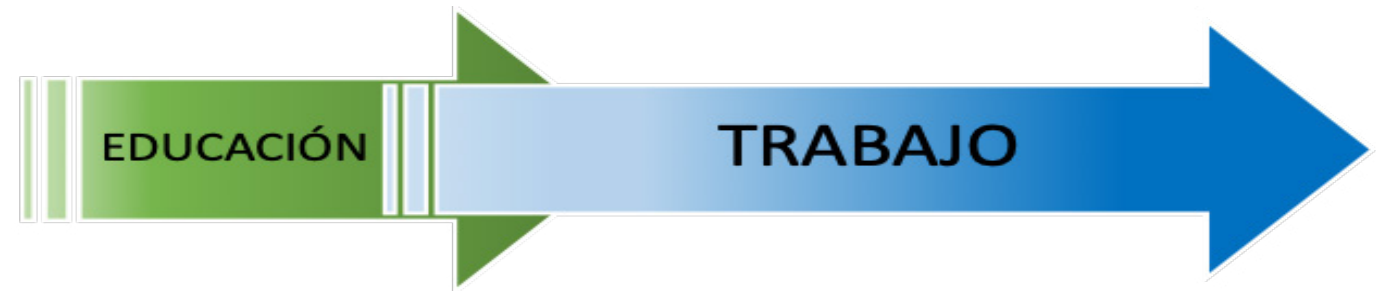

Fuente: Elaborado por los autores.

El Gráfico 2 visibiliza las trayectorias del grupo 2, donde se observa un desarrollo acotado al nivel medio y en ocasiones de la universidad en la trayectoria educativa con saberes enciclopédicos que se intensifican con el tiempo, pero de manera discontinua; $y$ una trayectoria laboral que comienza en paralelo a la formación secundaria o universitaria y que se va estabilizando de manera mayormente precaria o informal (aunque la formalidad se evidencia en algunos casos) a lo largo del tiempo.

\section{Trayectorias del grupo 3: itinerarios de la clase trabajadora obrera}

El grupo 3 se compone de obreros/as especializados/as y no especializados/as, que en general se encuentran asalariados/as y se desempeñan en establecimientos productivos de distintos tamaños.

Las personas entrevistadas provienen de familias que o bien son trabajadoras en ramas similares a las que ellas se emplean, 
Desigualdades sociales a contraluz: un análisis a partir de trayectorias de clase en Argentina Leticia Muñiz Terra • María Eugenia Ambort • Matías lucci

o bien su injerencia en el mundo laboral es por cuenta propia. Asimismo, cuentan con familiares y/o conocidos que los/as acercaron a los trabajos que poseen actualmente. Las personas que pertenecen a este grupo presentaban inserciones heterogéneas dentro del sector industrial, o bien se encontraban actualmente desempleadas, pero su principal ocupación ha sido en empresas contratistas de grandes empresas productivas.

Asistieron a escuelas primarias de carácter público emplazadas en el barrio donde vivían, ya que la cercanía facilitaba el traslado cotidiano entre el colegio y el hogar. Las escuelas secundarias a las que asistieron también eran públicas, pudiendo ser bachilleratos o escuelas técnicas. Quienes eligieron esta última opción lo hicieron en común acuerdo con los padres y comentaron que en sus hogares pensaban que ello brindaría mayores aprendizajes directamente vinculados con las exigencias del mercado laboral.

Algunas de las trayectorias educativas de la clase trabajadora obrera se vieron, por su parte, interrumpidas en el secundario, debido principalmente a la poca atención que prestaban a los estudios y al hecho de tener que trabajar. Ante esta situación, los/ as entrevistados/as cambiaron de colegio y pudieron terminar sin problemas, mientras otros/as abandonaron y no alcanzaron el final de los estudios medios.

Los recuerdos de los años vividos tanto en la primaria como en la secundaria evocaban y privilegiaban los amigos, los juegos, las reuniones, las salidas y los bailes. Se conjugaba así la valoración de un gran momento dentro del ciclo de vida (niñez/ juventud) con una alta consideración sobre aquello aprendido en la escuela. Entre los elementos especialmente mencionados por los/as entrevistados/as encontramos, por un lado, la capacidad de la escuela para conectar personas y establecer lazos de amistad hasta la actualidad y, por el otro, los aprendizajes realizados y las enseñanzas que perduraron para el resto de la vida. Los asistentes a escuelas técnicas mencionaron particularmente el acceso a algunas herramientas de última tecnología dentro de las aulas. 
Desigualdades sociales a contraluz: un análisis a partir de trayectorias de clase en Argentina Leticia Muñiz Terra • María Eugenia Ambort • Matías lucci

La escuela siempre te va a ayudar para cualquier ámbito de trabajo, por más que no sea en la especialidad que uno elija. En lo que es lo mío, en particular, lo que estoy trabajando actualmente, que es de electricista, en cámaras de seguridad, sí, ha aportado la parte de tecnicatura. Pero por ahí lo que está copado del colegio lo que yo veo que lo que influye en gran manera en parte del trabajo son, si se quiere, las amistades. (Entrevista No. 48)

En general, quienes pudieron finalizar la escuela secundaria intentaron continuar su trayectoria educativa en la universidad pública o en institutos terciarios de formación docente (también públicos). Estos estudios quedaron en su mayoría truncos, ya que se volvió difícil cumplir con las exigencias educativas para hacerlas compatibles tanto con las obligaciones laborales como así también con las de sus hogares. Sin embargo, varias personas entrevistadas señalaron que no se retiraron del todo de las aulas, ya que tuvieron que continuar estudiando en el marco de capacitaciones laborales de carácter obligatorio organizadas por las empresas donde se insertaron, en plan de adquirir mayores aptitudes y también al aspirar a ascensos en sus trabajos.

Dije "no es para mí", quizás por frustración, por ver que no pude encontrar las herramientas para... Si bien aprobaba parciales, no metí ningún final [...] Trabajaba y estudiaba, sí. Ahí se me hizo re complicado. Ahí como que decidí, dije "me dedico al trabajo, trabajo y chau". Siempre tuve como la loca idea de volver a estudiar algo, pero nunca lo puse en práctica. (Entrevista No. 30)

En cuanto a las trayectorias laborales, el ingreso al mercado ocupacional se dio en edades tempranas, ya sea en la niñez o durante la adolescencia. En algunos casos, el trabajo era importante para la organización y reproducción de las condiciones de vida hacia el interior del hogar. En otros, las primeras entradas fueron realizadas en función de ganar algo de dinero para sustentar gastos personales en la juventud. Las primeras experiencias fueron 
Desigualdades sociales a contraluz: un análisis a partir de trayectorias de clase en Argentina Leticia Muñiz Terra • María Eugenia Ambort • Matías lucci

informales, con arreglos de palabra y, en general, por poco tiempo. Fueron trabajos transitorios, entre los cuales pueden mencionarse: recolección de frutas, prestaciones en planes sociales, reparto de pizza o venta ambulante.

Después de estas primeras experiencias laborales, algunas trayectorias desembocaron en trabajos más estables, con contratos formalmente establecidos, seguridad social, remuneración de acuerdo al puesto y posibilidad de desarrollo de una carrera laboral. Estos se dieron, por ejemplo, en el marco de grandes empresas industriales de la región. El acceso a este tipo de trabajos fue logrado por contactos cercanos. Los amigos y familiares aportaron relaciones con gente que tenía capacidad de influencia para poder insertarse en el mercado ocupacional. Otros, por el contrario, consiguen sus trabajos de manera personal y valoraron especialmente su esfuerzo individual frente a las adversidades para alcanzar aquello que consideraban importante en materia laboral.

Estas trayectorias ocupacionales hantendido aser discontinuas, con muchos cambios de empleo a lo largo de la misma, en general como resultado de despidos. Los años 2001-2002, años de crisis económica, social y política del país, emergen como hitos en sus trayectorias: varios/as perdieron sus puestos de trabajo a raíz de la reestructuración de las empresas en las que trabajaban, y pasaron un tiempo como desempleados/as. La desocupación fue en estos casos por un período breve, pues ante los despidos se refugiaron en trabajos informales y changas, como forma de continuar en actividad, desplegando los saberes y oficios aprendidos tanto en el sistema educativo como en sus experiencias laborales anteriores.

En general, cuentan con un conjunto de habilidades y saberes aprendidos tanto formal (en la escuela técnica) como informalmente (aprendiendo en la calle, junto a quienes conocen los oficios), a los que recurren en momentos de dificultad. Para algunos/as, el momento de despido fue un tiempo para volver a los trabajos domiciliarios en electricidad, lavar autos o repartir pizzas. Un elemento que marcó por igual sus experiencias laborales es 
Desigualdades sociales a contraluz: un análisis a partir de trayectorias de clase en Argentina Leticia Muñiz Terra • María Eugenia Ambort • Matías lucci

el riesgo que corren en el trabajo. Tanto para quienes trabajan en la calle como para quienes lo hacen dentro de una empresa, sus cuerpos (y también sus vidas) parecen fácilmente vulnerables y desprotegidas. Las entrevistas cuentan con relatos sobre robos, pistolas y asaltos fugaces a camiones de reparto, y también el vértigo de trabajar en alturas o entrar a cámaras en contacto con ácido sulfúrico, como parte de la cotidianeidad.

Gráfico 3. Trayectorias de clase trabajadora obrera (TC3)

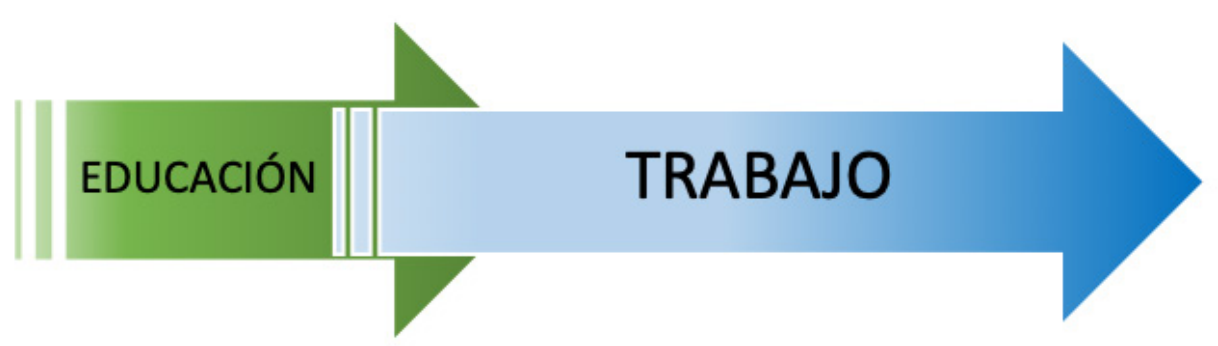

Fuente: Elaborado por los autores.

El Gráfico 3 muestra las trayectorias del grupo 3, donde se observa un desarrollo acotado al nivel medio en la trayectoria educativa en la que prima la formación técnica y el desarrollo discontinuo de estudios universitarios. La trayectoria laboral se inicia en paralelo a la formación media y se va estabilizando de manera mayormente precaria o informal a lo largo del tiempo.

\section{Trayectorias del grupo 4: recorridos de la clase trabajadora informal}

Este grupo está conformado por trabajadores/as informales y domésticos/as. Es el sector con mayor inestabilidad y precariedad en relación a los ingresos, al nivel de instrucción requerida, a las formas de contratación, y a las entradas y salidas del mercado de trabajo. Se caracteriza fundamentalmente por la ausencia de un salario estipulado y de la mayoría de los derechos laborales básicos. Son trabajadores/as por cuenta propia, que se autoexplotan para conseguir los recursos necesarios para mantenerse a sí mismos/ 
Desigualdades sociales a contraluz: un análisis a partir de trayectorias de clase en Argentina Leticia Muñiz Terra • María Eugenia Ambort • Matías lucci

as y a sus familias. Entre las personas entrevistadas, encontramos a empleadas domésticas, pequeños/as productores rurales, costureras, vendedores ambulantes, cooperativistas perceptores de un programa social y cuida-coches. Muchas de ellas tienen un origen migrante, provienen de países latinoamericanos limítrofes como Bolivia y Paraguay, y han llegado a la Argentina en busca de mejores condiciones laborales. En general, la familia de sus padres tenía un origen rural, prácticamente sin acceso al sistema educativo, y con muy pocos recursos económicos.

La mayoría de las familias de origen de los/as entrevistados/ as eran numerosas, con varios hijos/as (entre 4 y 10) que, desde la temprana infancia, "ayudaban" en el trabajo doméstico y extradoméstico (cuidando animales, vendiendo en ferias o en la calle, ayudando a cocinar o en la construcción). En varios casos se repetía también que, ante la imposibilidad de mantener a toda la prole, la estrategia era enviar a los/as niños/as a la ciudad, bajo la tutela de algún familiar o conocido, que les diera casa y comida (y también educación) a cambio de trabajo (ya sea cocinar, limpiar, cuidar niños/as, cuidar animales, sembrar).

La necesidad de comenzar muy tempranamente a trabajar (a los 12 años o antes) implicó que las trayectorias educativas fueran, en general, muy cortas. La mayoría terminó la primaria y luego, ante la necesidad de generar ingresos, tanto para el propio sustento como de la familia, abandonaron los estudios. También ha habido casos en los que los/as entrevistados/as identificaron cierta "vagancia" para el estudio, o falta de estímulos al interior del hogar, que les llevaron a optar por dejar la escuela y así comenzar a trabajar. Todas las personas entrevistadas tenían una alta valoración por la educación escolar, y hubieran querido continuar con sus estudios. Algunas los han retomado en los programas de finalización educativa para adultos, mientas otras señalaban que han tenido una segunda oportunidad al vivir la experiencia del aprendizaje escolar junto a sus hijos/as.

Los años de escuela en la infancia son recordados con agradecimiento, a pesar de que -principalmente para los y las 
Desigualdades sociales a contraluz: un análisis a partir de trayectorias de clase en Argentina Leticia Muñiz Terra • María Eugenia Ambort • Matías lucci

migrantes- los maestros eran muy exigentes y de que incluso percibían castigos físicos. La escuela fue evocada como un ámbito en el que recibieron ayudas y estímulos para continuar estudiando, y donde les fueron inculcados conocimientos básicos de lectoescritura y cálculo, y también valores que les acompañaron por el resto de su vida: el respeto, el saludo y la buena presencia. En algunos casos, los oficios aprendidos en la escuela fueron un aporte importante para la posterior inserción laboral.

Las habilidades y destrezas desplegadas actualmente en el mercado laboral han sido adquiridas, en general, de manera informal. Muchas de ellas transmitidas en el seno familiar como oficios, tareas u obligaciones domésticas, ya sea limpieza, lavado de ropa, cuidado de niños/as, cocina, agricultura, venta ambulante o construcción. También se identificaron como importantes los aprendizajes adquiridos durante la pubertad/adolescencia por patrones o compañeros/as de trabajo en sus primeras incursiones en el mundo laboral, como costura, gastronomía, construcción, electricidad o carpintería; o por las patronas, que empleaban a las mujeres cama adentro para el servicio doméstico.

En este punto es muy importante recalcar la diferenciación entre varones y mujeres, ya que todas las entrevistadas se han desempeñado como trabajadoras domésticas en algún momento de su trayectoria (ya sea en la cocina, en el cuidado de niños o personas mayores, o en la limpieza), mientras los varones han sido asignados a trabajos manuales como mantenimiento, gomería y lavado de autos, agricultura, venta ambulante, construcción, etc. La forma de aprendizaje ha sido, en todos los casos, la observación, mirar cómo lo hacían otros, así como la prueba y error.

Había otras chicas que trabajaban ahí. Mirándolas, así aprendí. Aprendí a cocinar, y después de ahí entré a trabajar en otra, que me pagaban un poquito más, mientras trabajaba de cocinera. Y bueno, sabiendo trabajar de todo, elegía el trabajo que más me convenía, cuando quería ganar un poco más. (Entrevista No. 12) 
Desigualdades sociales a contraluz: un análisis a partir de trayectorias de clase en Argentina Leticia Muñiz Terra • María Eugenia Ambort • Matías lucci

En relación a las trayectorias laborales, todas se caracterizan por las múltiples entradas y salidas del mercado de trabajo, en general en la búsqueda de mayor estabilidad o de mejores condiciones. Es llamativo que prácticamente no se mencionaron períodos sin trabajar, ya que el trabajo era una condición necesaria para la reproducción del día a día. Todos (o prácticamente todos) los trabajos han sido informales, conseguidos a través de redes de parentesco o recomendaciones de personas conocidas. Existe una alta rotación por varios rubros, todos informales y de trabajos manuales. En los casos en que han ingresado como trabajadores/as formales, estos empleos han sido de corta duración y abandonados por voluntad propia debido a las duras condiciones laborales. En sus relatos, los/as entrevistados/as expresaban sentirse más cómodos/as trabajando por su cuenta, en algunos casos al aire libre, controlando sus propios horarios, en vez de depender de un jefe o tener que cumplir un horario estricto, que en general era de mucha carga horaria a cambio de poco dinero.

\section{3}

Lo bueno es que fue mi primera experiencia, después lo dejé porque vi que era mucho trabajo y poca paga... uno se va despertando y viendo, al principio me sirvió, y era un paso. Así y todo, estudiaba. (Entrevista No. 33)

Este cuentapropismo, por otro lado, les permitía también conciliar trabajo productivo y reproductivo, y sobre todo para el caso de las mujeres, trabajar y criar a los/as hijos/as estando presentes. Tanto para las que son costureras como las que son trabajadoras rurales, la coincidencia del lugar de trabajo con el hogar es para ellas una ventaja en el sentido de poder estar más tiempo con ellos/as y no tener que delegar esa tarea en otras personas. Ésta también es una estrategia que se da como respuesta a la falta de instituciones públicas de educación para la primera infancia. Asimismo, las empleadas domésticas por horas también lo consideran una estrategia para poder trabajar menos y dedicar más tiempo al cuidado de otros miembros de la familia, como ancianos/as o enfermos/as. En el caso de los varones, el 
Desigualdades sociales a contraluz: un análisis a partir de trayectorias de clase en Argentina Leticia Muñiz Terra • María Eugenia Ambort • Matías lucci

aprendizaje del oficio de albañil o electricista se dio sobre todo con el objetivo de construir la propia vivienda, y luego quedó como un conocimiento puesto en valor en el mercado de trabajo, a modo de "changas".

Si bien todos/as han expresado un claro deseo de prosperar y superarse, la mayoría se expresa conforme con el lugar en el que está y el trabajo que tiene. Sienten (y manifiestan) que se han ido superando a lo largo de su trayectoria laboral, principalmente si lo comparan con su situación económica y familiar en la infancia, o la de sus padres, y no aparece en sus relatos un deseo de asimilarse a otra clase social. Sí recalcan, en el caso de las familias que viven muy precariamente en casillas de madera o sin acceso a algunos servicios públicos básicos, el deseo de mejorar esas condiciones habitacionales. Sin embargo, se manifiestan muy flexibles y abiertos/as a la posibilidad de tener que cambiar de actividad si la actual no les es redituable. El "saber trabajar" aparece como un valor en sí mismo y una trinchera de seguridad frente a la incertidumbre.

\section{4}

Por ahí también puedo cambiar el trabajo, pero yo estoy bien en la quinta. Pero sí me va mal en la quinta tampoco me quedaría nada. Ahí tengo que aguantar, porque no tengo mis estudios. Puedo cambiar el trabajo. Y cambiaría de trabajo, trabajaría en otra cosa que me vaya bien. (Entrevista No. 22)

Gráfico 4. Trayectorias de clase trabajadora informal (TC4)

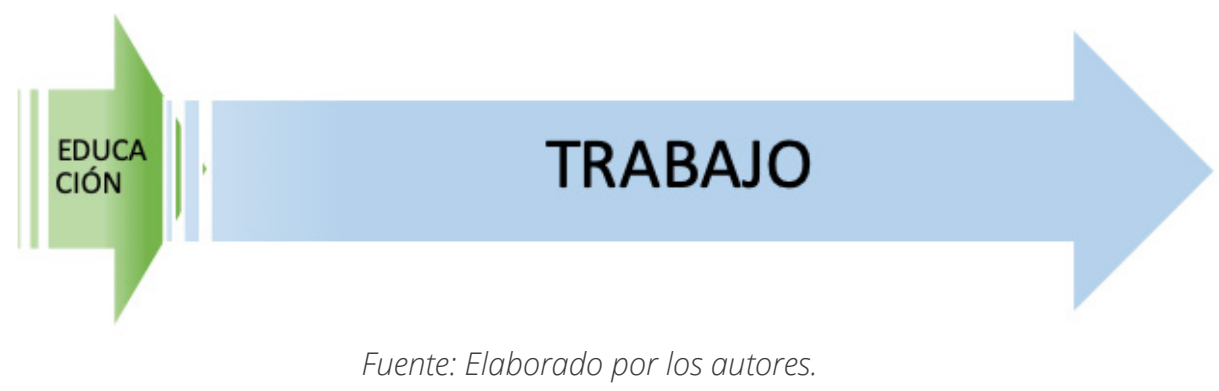

El Gráfico 4 visibiliza las trayectorias del grupo 4 en donde se observa una trayectoria educativa reducida a la educación 
Desigualdades sociales a contraluz: un análisis a partir de trayectorias de clase en Argentina Leticia Muñiz Terra • María Eugenia Ambort • Matías lucci

primaria y una trayectoria laboral que se inicia en la infancia o en la adolescencia y permanece en la informalidad de forma permanente.

\section{Reflexiones finales}

Una vez caracterizada cada una de las trayectorias de las clases sociales identificadas, en estas reflexiones finales proponemos una lectura analítica a contraluz, es decir, contrastando las particularidades de las clases identificadas para comprender las desigualdades sociales.

Comenzamos así señalando que la clase media alta, que se encontraba en la cúspide de la estructura social, presentaba trayectorias educativas y laborales relativamente homogéneas, alcanzando los máximos niveles educativos posibles (posgrados) y cargos jerárquicos en sus puestos de trabajo, asociados a la vez a sus carreras profesionales y con las mejores condiciones de contratación, de estabilidad y seguridad social. Sus trayectorias mostraban linealidad en términos educativos, en tanto se expresaban a partir de transiciones pautadas y sincronizadas, siguiendo las expectativas y los tiempos institucionalizados por las políticas educativas del país.

Mostraban así homogeneidad en sus condiciones laborales, ya que siempre poseían estabilidad y seguridad social. Sus trayectorias eran lineales y de ascenso, pues ya sea en el sector público o privado, sólo en uno o alternando, alcanzaban puestos de responsabilidad o jerárquicos con personal a cargo. En estas carreras se ponían en juego tanto los saberes adquiridos en las instituciones educativas formales como en capacitaciones extracurriculares (sobre todo el aprendizaje de idiomas), y también habilidades actitudinales relacionadas con la "gestión de sí" (proactividad, flexibilidad, predisposición, autogestión). Saberes y habilidades que iban asentando ventajas acumulativas que se traslucían en sus posiciones de prestigio y de poder. 
Desigualdades sociales a contraluz: un análisis a partir de trayectorias de clase en Argentina Leticia Muñiz Terra • María Eugenia Ambort • Matías lucci

En algunos casos, las condiciones de la familia de origen aportaron una estructura disponible de posiciones (económicas, culturales, profesionales), mientras que en otros casos se produjo una movilidad ascendente respecto de la clase de los padres, basada sobre todo en la institucionalidad asociada a la educación pública en todos los niveles y a un contexto laboral estatal o empresarial favorable. No obstante, el encadenamiento de oportunidades para el ascenso/éxito no fue identificado como una ventaja estructural por las personas entrevistadas, sino como producto del esfuerzo personal, las capacidades propias y adquiridas y la voluntad de crecer y superarse, o incluso del azar.

Las clases medias trabajadorasy las clases trabajadoras obreras pueden agruparse, por su parte, como "clases intermedias", ya que presentaban algunas similitudes en relación a los niveles educativos alcanzados y a las posibilidades de movilidad social desplegadas en sus trayectorias. La mayor diferencia entre estos grupos tiene que ver con los tipos de trabajo que realizaban, imitando la ya tradicional distinción entre trabajadores/as de "cuello blanco" y de "cuello azul", según realizaran trabajos manuales e industriales, o asociados a la administración y los servicios. Para ambos grupos, la trayectoria educativa incluyó la culminación de la escuela secundaria y la incursión en estudios universitarios y terciarios. La obtención del título secundario implicó una superación del nivel educativo alcanzado por los padres, y el ingreso a la universidad fue realizado con sacrificio y combinado con la necesidad de trabajar para poder hacerlo. El nivel de las escuelas secundarias, así como la temprana inserción laboral de estos grupos, presentaron dificultades para el desempeño "esperado o ideal" de las carreras universitarias, y muchas veces supusieron inclusive su abandono.

Las trayectorias laborales de las clases medias trabajadoras eran heterogéneas, asociadas a puestos administrativos formales públicos o privados o trabajo por cuenta propia, con formas precarias de contratación, pero que permitían alcanzar cierta estabilidad y acceso a la seguridad social, aunque no a una carrera laboral ascendente. Las redes familiares y de conocidos/as constituyeron 
Desigualdades sociales a contraluz: un análisis a partir de trayectorias de clase en Argentina Leticia Muñiz Terra • María Eugenia Ambort • Matías lucci

un soporte para las búsquedas laborales y la contratación, a través de las recomendaciones. Si bien poseían ciertas credenciales educativas, como el título secundario (bachiller), o en algunos casos también el universitario, éstas no se conjugaron necesariamente como ventajas a la hora de obtener mejores puestos de trabajo. Realizaban trabajos administrativos o de servicios, ya sea en el sector público, privado o trabajo por cuenta propia.

La clase trabajadora obrera, en cambio, valoraba los aprendizajes y las credenciales educativas, ya sea los de la escuela secundaria (en varios casos escuela técnica) o de la universidad, como dinamizadores de oportunidades en el mercado laboral. La trayectoria laboral se iniciaba del mismo modo con trabajos informales, de mayor precariedad, pero posteriormente evolucionaban hacia empleos formales y de mayor estabilidad. Los empleos obtenidos (y aspirados) se correspondían con los oficios aprendidos, y la inserción laboral se daba principalmente en el sector industrial, ya sea en grandes empresas o en pequeñas firmas propias. A diferencia de las otras clases, los individuos de este grupo tenían muy presente la peligrosidad que involucraban las tareas que se les asignan, ya que ponían en riesgo su cuerpo (y su vida) en repetidas ocasiones. Asimismo, esta clase es una de las que tiene más presente (en sus relatos, y en sus trayectorias) el contexto macro-social, principalmente las crisis de 2001 y la actual (2015-2019), como períodos en que sufren despidos de sus trabajos estables, significando un quiebre en la carrera y las condiciones laborales. La estrategia ante esta situación fue el cuentrapropismo, ejerciendo los oficios aprendidos mediante "changas" o micro-emprendimientos.

La clase trabajadora informal, ubicada en la base de la estructura social, se caracterizaba por poseer pocas credenciales educativas (en algunos casos primario incompleto, y en otros secundario incompleto), y trayectorias laborales muy extensas, que se iniciaban en el período infantil (antes de los 12 años de edad). Las trayectorias presentaban una alta rotación por muchos y diversos empleos, todos ellos precarios e informales, asalariados o por cuenta propia, y en general manuales o asociados al trabajo 
Desigualdades sociales a contraluz: un análisis a partir de trayectorias de clase en Argentina Leticia Muñiz Terra • María Eugenia Ambort • Matías lucci

doméstico. Las habilidades necesarias para la ejecución de estas tareas fueron adquiridas de manera empírica e informal, a través de la observación y de la práctica y error.

En general, la posición de las personas que corresponden a este grupo supone una movilidad social ascendente respecto de su familia de origen, sin acceso a la educación formal y con un origen rural muy pobre. Sin embargo, la rotación laboral señalada no implicaba necesariamente para este grupo un ascenso social sino, según lo expresado en los relatos, la búsqueda de mitigar las condiciones de explotación y una mayor autonomía en el manejo de los propios tiempos. Así, la auto-explotación era preferida antes que el asalariamiento. El cuentapropismo era una estrategia, entonces, para garantizar por un lado la continuidad laboral y, por otro lado, para conciliar trabajo en el mercado de trabajo (productivo) con trabajo reproductivo y de cuidados.

En esta clase social las redes adquirieron un papel fundamental en las trayectorias vitales como canalizadoras de posibilidades laborales y también migratorias. La familia, los conocidos, las relaciones de compadrazgo y también los movimientos sociales aparecen en todos los relatos como facilitadores de conocimientos, recomendaciones y oportunidades laborales y diversos tipos de ayudas que garantizan la reproducción del grupo familiar.

Para finalizar, podemos señalar, que el grupo que se encontraba en la cúspide de la estructura social va ensamblando de manera ventajosa lo educativo con lo laboral, apropiándose de soportes institucionales y familiares que se encontraban presentes en su itinerario (políticas educativas y laborales de nivel nacional y recursos familiares); mientras las clases intermedias, al tener menores soportes institucionales y familiares disponibles, fueron acoplando de manera irregular las dimensiones educativa y laboral, pudiendo hacer uso o no de sus formaciones en el mundo del trabajo. El grupo que se encontraba en la base de la estructura social se vio, por su parte, prácticamente imposibilitado de imbricar la educación con el trabajo en sus trayectorias, pues las escasas posibilidades y soportes institucionales y familiares 
Desigualdades sociales a contraluz: un análisis a partir de trayectorias de clase en Argentina Leticia Muñiz Terra • María Eugenia Ambort • Matías lucci

que tenían a disposición los condenaban a caminos caracterizados por un encadenamiento permanente de desventajas y privaciones.

Gráfico 5. Síntesis comparada de las distintas trayectorias de clase y las dimensiones macro y meso-social

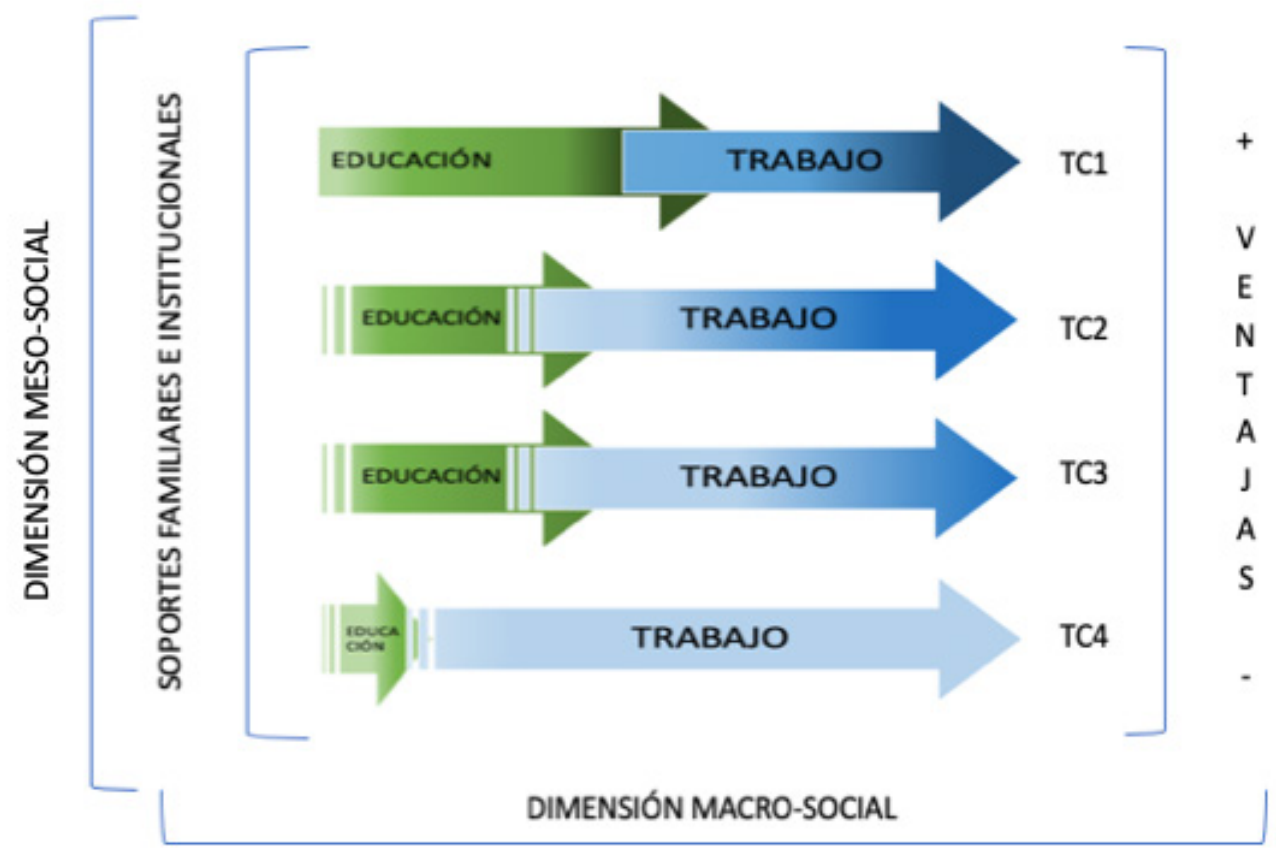

HETEROGENEIDAD ESTRUCTURAL

Fuente: Elaborado por los autores.

Las trayectorias educativas y laborales de las clases sociales analizadas visibilizan las diferentes maneras en que desde lo micro-social -es decir desde las representaciones de los actores sociales sobre su vida- se interpreta y da forma al acoplamiento diacrónico entre lo educativo y lo ocupacional (con lo familiar), conformando trayectorias diversas en las cuales las escalas macro y meso-sociales adquieren presencia y relevancia, aunque esto no siempre sea percibido por los actores sociales. Diversidad que cristaliza, en síntesis, la forma en que las múltiples desigualdades de clase se van produciendo y reproduciendo en la temporalidad. 
Desigualdades sociales a contraluz: un análisis a partir de trayectorias de clase en Argentina Leticia Muñiz Terra • María Eugenia Ambort • Matías lucci

\section{Referencias}

BÁRCENA, Alicia; PRADO, Antonio. Heterogeneidad estructural y brechas de productividad: de la fragmentación a la convergencia. In: COMISIÓN ECONÓMICA PARA AMÉRICA LATINA Y EL CARIBE CEPAL. Documento La hora de la igualdad. Brechas para cerrar, caminos por abrir. Santiago de Chile: CEPAL, 2010. p. 91-130.

BECK, Ulrich; BECK GERNSHEIM, Elisabeth. La individualización. El individualismo institucionalizado y sus consecuencias sociales y políticas. Barcelona: Paidós. 2003.

BERTAUX, Daniel. Biography and society. The life history approach in the social sciences. London/Berkeley: SAGE, 1981.

BOURDIEU, Pierre. La distinción. Criterios y bases sociales del gusto. Buenos Aires: Taurus, 2012.

DALLE, Pablo. Movilidad social desde las clases populares. Un estudio sociológico en el Área Metropolitana de Buenos Aires (1960-2013). Buenos Aires: Universidad de Buenos Aires/CLACSO, 2016.

DUBET, François. Repensar la justicia social. Buenos Aires: Siglo XXI, 2011.

ERIKSON, Robert; GOLDTHORPE John. The constant flux: a study of class mobility in industrial societies. Oxford: Oxford University Press, 1993.

GIDDENS, Antony. La estructura de las clases en las sociedades avanzadas. Madrid: Alianza, 1979.

GODARD, Francis. Uso de las historias de vida en las ciencias sociales. In: LULLE, Thierry; VARGAS, Pilar; ZAMUDIO, Lucero (coord.) Los usos de la historia de vida en las ciencias sociales. Bogotá: Anthropos, 1998. p. 5-55.

GOFFMAN, Erving. La presentación de la persona en la vida cotidiana. Buenos Aires: Amorrortu, 1981. 
GOLDTHORPE, John. Social mobility and class structure in modern Britain. Oxford: Clarendon Press, 1987.

GRASSI, Estela; HINTZE, Susana. Tramas de la desigualdad. Buenos Aires: Prometeo, 2018.

JELIN, Elizabeth. Desigualdades de clase, género y etnicidad/raza. Realidades históricas, aproximaciones analíticas. Berlin: desiguALdades.net International Research Network on Interdependent Inequalities in Latin America, 2014. (desiguALdades. net Working Paper Series n. 73).

MARTUCCELLI, Danilo; DE SINGLY, François. Las sociologías del individuo. Santiago de Chile: LOM, 2012.

MUÑIZ TERRA, Leticia. Carreras y trayectorias laborales: una revisión crítica de las principales aproximaciones teórico-metodológicas para su abordaje. Revista Latinoamericana de Metodología de las Ciencias Sociales, v. 2, n. 1, p. 36-55, 2012. MUÑIZ TERRA, Leticia. Biographical events and milestones: a methodological proposal to analyze narratives of life. Forum: Qualitative Social Research, v. 19, n. 2, p. 1-25, 2018.

PATTON, Michael Quinn. Qualitative evaluation and research methods. Thousand Oaks, CA: SAGE, 2002.

PLA, Jessica. Condiciones objetivas y esperanzas subjetivas. Buenos Aires: Autores de Argentina, 2016.

REYGADAS, Luis. Las redes de la desigualdad: un enfoque multidimensional. Política y Cultura, n. 22, p. 7-25, 2004.

SALVIA, Agustín. Heterogeneidad estructural y desigualdad social en la Argentina de las últimas dos décadas de historia económica. Revista de investigación en Ciencias Sociales, n. 84, p. 46-55, 2013.

SARAVÍ, Gonzalo. Juventudes fragmentadas: socialización, clase y cultura en la construcción de la desigualdad. México, DF: FLACSOMéxico, 2015. 
